\title{
POLÍTICA NACIONAL DE SAÚDE INTEGRAL LGBT: O QUE OCORRE NA PRÁTICA SOB O PRISMA DE USUÁRIOS (AS) E PROFISSIONAIS DE SAÚDE
}

Francisco Jander de Sousa Nogueira

Docente Adjunto do Curso de Medicina da Universidade Federal do Piauí - Campus Parnaíba. Membro do Centro Brasileiro de Estudos de Saúde - CEBES. Brasil.

\section{Thalia Ariadne Peña Aragão}

Acadêmica do Curso de Psicologia da Universidade Federal do Piauí - UFPI, Campus Ministro Reis Veloso - CMRV. Brasil
Autor correspondente

Thalia Ariadne Peña Aragão

thaliariadne.pena@gmail.com
RESUMO: Com o intuito de reparar a desassistência, promover saúde integral, equidade e atender à população LGBT de forma efetiva, a Política Nacional de Saúde Integral de Lésbicas, Gays, Bissexuais, Travestis e Transexuais (PNSILGBT) foi sancionada em 2011. Apesar de sua existência, o acesso desse público à saúde ainda hoje é restrito. Logo, o presente estudo se caracteriza como uma pesquisa qualitativa que tem por objetivo analisar os desafios atuais no tocante ao atendimento e acesso da população LGBT aos serviços de saúde. Os dados foram coletados a partir de entrevistas semiestruturadas com profissionais de saúde de uma instituição hospitalar da cidade de Parnaíba-PI e travestis/ transexuais usuárias que buscaram esse e outros dispositivos de saúde. Para análise do material coletado, foi utilizada a Análise de Discurso. Pretende-se, a partir da identificação e compreensão das restrições da PNSILGBT neste contexto, auxiliar na busca de práticas alternativas para a ampliação do acesso dessa população à saúde.

PALAVRAS-CHAVE: Determinação social; Estigma; Saúde; Minorias sexuais e de gênero.

\section{BRAZILIAN POLICY OF LGBT INTEGRAL HEALTH: WHAT ACTUALLY HAPPENS FROM THE POINT OF VIEW OF AGENTS AND HEALTH PROFESSIONALS}

ABSTRACT: The Brazilian Policy for the Integral Health of Lesbians, Gays, Bisexuals, Travesties and Transsexuals (PNSILGBT) was published in 2011 to repair the lack of assistance and to promote integral health and equality, and attend to the LGBT population effectively. However, the population's access to health is still very limited. Current study is a qualitative research to analyze current challenges with regard to attendance and access to LBGT populations to health services. Data were retrieved by half-structured interviews with health professionals of a hospital in Parnaiba PI Brazil and by travesties and transsexual people who required health schemes. Collected material was analyzed by Discourse Analysis. Through the identification and comprehension of PNSILBGT restrictions, one may seek alternative practices to amplify health access of the population concerned.

KEY WORDS: Social Determination; Stigma; Health; Sexual and Gender Minorities.

\section{INTRODUÇÃO}

A década de 90 é marcada pela criação da lei $n^{0} 8.080$, que regulamenta o Sistema Único de Saúde (SUS), reafirma a saúde como direito e dispõe, dentre outros, sobre as condições para a sua promoção, 
proteção e recuperação. Atualmente, o conceito de saúde está relacionado ao bem-estar físico, social e mental. Entretanto, apesar de passadas quase três décadas da regulamentação do Sistema, o acesso universal, integral e igualitário à saúde, tal como consta em sua legislação, ainda tem sido um desafio para a gestão, trabalhadores e população.

A população de lésbicas, gays, bissexuais, travestis e transexuais foi por muito tempo mais um grupo desassistido, excluído, alvo de discriminação, preconceito, associado ao HIV/AIDS e à prostituição. Ademais, atualmente se encontra um grande número de produções científicas reforçando tal associação.

Após diversas lutas e movimentos travados ao longo dos anos pelo universo LGBT, o enfrentamento de tais mazelas, em consonância com o que é trazido por Carrara ${ }^{1}$, deve ser um processo ativo, que ocorra a partir da garantia de direitos dessas minorias sexuais, destacando a difusão de dispositivos que coíbem a discriminação e favorecem a ampliação de direitos sociais e civis como possibilidade, rompendo assim com a exclusividade heterossexual dominante.

$\mathrm{Na}$ tentativa de reparar a desassistência, promover saúde integral, equidade e ações para minimizar o preconceito e atender a essa população que possui necessidades específicas, a política nacional de saúde integral de lésbicas, gays, bissexuais, travestis e transexuais (Política Nacional de Saúde Integral LGBT) ${ }^{2}$ foi sancionada em 2011, com o intuito de que se voltassem os olhares, especificamente no âmbito da saúde, para as demandas desse universo.

Neste estudo, o foco é averiguar a efetivação da Política Nacional de Saúde Integral LGBT e os possíveis entraves para a incorporação dessa política no dia a dia dos dispositivos de saúde, mais precisamente a partir da experiência de travestis e transexuais e do olhar de profissionais de um hospital estadual de urgência e emergência. A análise desses fatores se dá a partir de relatos e experiências de profissionais e usuárias no sistema de saúde da cidade de Parnaíba-PI. Para isso, atentou-se para a determinação social, estigma e preconceitos direcionados à população LGBT e possíveis impactos para o acesso à saúde.

\section{METODOLOGIA}

A concepção deste estudo tem como referência o método etnográfico, por identificar o vasto processo de disseminação dos métodos qualitativos na área da saúde, buscando assim novos referenciais teórico-metodológicos que deem conta de seus objetos ${ }^{3}$.

Para coleta dos dados, foram utilizadas as técnicas da observação participante, produção sistemática de diários de campo e entrevistas. Após a construção dos instrumentos de pesquisa, realizaram-se entrevistas semiestruturadas direcionadas a dois públicos: usuárias travestis/transexuais e profissionais de saúde. Para a análise dos dados coletados, realizou-se uma oficina dentro das atividades do Grupo de Estudos em Antropologia, Saúde e Sexualidade da Universidade Federal do Piauí, Campus ministro Reis Velloso. Nessa oficina, buscou-se, a partir da análise de discurso, extrair categorias analíticas para o processo de análise dos dados coletados e, em seguida, discutir e analisar as entrevistas a partir das transcrições e percepções dos pesquisadores e da literatura estudada.

Sendo assim, a amostra é composta por um primeiro público, os profissionais do Hospital Estadual Dirceu Arcoverde (HEDA) da cidade de Parnaíba-PI (trabalhadores do Pronto-Socorro, os quais estão em contato direto com os(as) usuários(as) da população LGBT que buscam os serviços de urgência e emergência do hospital).

O hospital HEDA foi inaugurado em 1991 e atualmente conta com 152 leitos divididos em nove especialidades médicas (clínica médica, pediatria, obstetrícia, ortopedia, cirurgia geral, UTI, prontosocorro, unidade de terapia semi-intensiva neonatal, neonatologia), seis consultórios, cinco salas no centro cirúrgico e obstétrico. A instituição atende à Planície Litorânea do Piauí, a qual é composta por 11 municípios, além de municípios pertencentes a Estados vizinhos (Maranhão e Ceará).

O segundo público é justamente a população LGBT usuária, não só especificamente da atenção terciária, mas também do sistema de saúde como um todo. Neste estudo, contou-se com a participação de quatro usuárias do sistema de saúde que se identificavam como transexuais e travestis residentes da cidade de Parnaíba-PI. Com as usuárias, buscava-se conhecer as 
possíveis potenciais e dificuldades vivenciadas nos dispositivos de saúde frequentados. A dupla composição da amostra se justifica pela necessidade - do ponto de vista do pesquisador - de que a análise seja realizada a partir de dados vindos de perspectivas diferentes e sejam comparados.

Esbarrou-se com a dificuldade na realização das entrevistas: no contexto hospitalar, os profissionais demonstravam receio de se expor e expor a instituição; além do mais, relatavam falta de tempo, pois as entrevistas eram realizadas em meio aos plantões. Quanto às usuárias entrevistadas (travestis e transexuais femininas), por diversas vezes tivemos que remarcar e/ou desmarcar entrevistas, seja por indisponibilidade, seja por receio das mesmas em participar da pesquisa, constatando-se ser reflexo do acúmulo de situações de preconceito e violência já experienciadas por esses sujeitos.

A primeira amostra esteve composta por dois enfermeiros, uma técnica em enfermagem, uma assistente social e duas recepcionistas da instituição de saúde. As perguntas direcionadas a eles eram abertas, de forma que a entrevista era conduzida a partir do que estava sendo trazido pelos entrevistados, a fim de que se explorasse mais o que interessasse à área temática da pesquisa. Foram feitas perguntas sobre o conhecimento e a prática da política LGBT, tipos de violências presenciadas ou vividas - além da investigação da violência institucional velada -, opinióes acerca da política e a prática da integralidade nos dispositivos da saúde. Exploraramse também na entrevista quais seriam as demandas responsáveis por levar essa população ao hospital. Além disso, os questionamentos giravam em torno de possíveis situações de preconceito praticadas/ocorridas na instituição. Analisaram-se as entrevistas para além do que foi dito, com a Análise do Discurso (AD).

[...] pode-se afirmar que o corpus da $\mathrm{AD}$ é constituído pela seguinte formulação: ideologia + história + linguagem. Aideologia é entendida como o posicionamento do sujeito quando se filia a um discurso, sendo o processo de constituição do imaginário que está no inconsciente, ou seja, o sistema de idéias que constitui a representação; a história representa o contexto sóciohistórico e a linguagem é a materialidade do texto gerando 'pistas' do sentido que o sujeito pretende dar: ${ }^{4: 680-1}$.
A análise de discurso admite a linguagem longe de ser neutra, ou seja, a linguagem é um meio que demonstra a construção social e cultural dos sujeitos ${ }^{5}$. O sujeito é produzido; não é dono, muito menos a origem daquilo que diz, mas tem a ilusão de sê-lo ${ }^{6}$. Dessa forma, a análise teve o objetivo de investigar os sentidos estabelecidos nos seus diferentes modos de exteriorizarse durante as entrevistas, os quais foram verbais e não verbais; bastou-se, para isso, que tais sentidos fossem percebidos e captados para então serem interpretados. Todo o método esteve de acordo com a literatura trabalhada ao longo do processo de trabalho, com o conteúdo discursivo trazido pelos sujeitos entrevistados e com as vivências e observações do pesquisador durante a imersão no âmbito da saúde.

Este estudo foi aprovado pelo Comitê de Ética e Pesquisa da Universidade Federal do Piauí, Campus ministro Petrônio Portella, com o número de registro 2.527 .830 .

\section{RESULTADOS}

Após a análise e comparação das entrevistas, percebeu-se em comum entre profissionais e usuárias o desconhecimento da existência da Política Nacional de Saúde Integral LGBT, assim como dos direitos garantidos a esse público por meio dessa e de outras políticas no que diz respeito à saúde. Apesar do SUS ser uma conquista da população e depender da participação social para o seu planejamento e gestão, seus princípios ainda são pouco conhecidos pelos brasileiros. Nesse sentido, a constante (re) construção e melhora desse sistema se dá também por meio da participação popular nas conferências e conselhos de saúde?

As usuárias relatam ter vivido situações de preconceito nos dispositivos de saúde em que buscaram assistência. Por exemplo, uma das entrevistadas que se reconhece como mulher trans descreve uma dessas vezes:

\footnotetext{
É porque dia da mulber é na quintafeira e dia do bomem é na sexta. E se eu quisesse ser atendida por ela eu tinba que ir no dia do bomem. Aí eu peguei e disse pra ela (trabalhadora do dispositivo de saúde): mulber, pois eu não vou no dia do bomem não, eu vou no dia da mulher. (A
} 
trabalhadora disse) que não era pra eu ir no dia da mulber não, que tinba muita mulher, não sei o que mais lá! Aí eu fui (na quinta). Ela negou atendimento. Eu tive que ir na sexta e ainda fui (atendida) depois de todos os bomens. (Usuária 2)

Quanto aos profissionais, percebeu-se certo distanciamento entre eles e as usuárias do universo LGBT. Em todas as entrevistas realizadas, a polaridade nós/eles estava presente nos discursos de forma enfática. Nos relatos/falas de todos os trabalhadores entrevistados, constatou-se a pouca importância dada às necessidades de saúde específicas do grupo quando esses prestadores de assistência diziam tratar a todos os pacientes da instituição sem qualquer distinção e entender que a política fora criada com esse intuito.

[...] eu não faço diferença no atendimento pra eles (população LGBT). Porque quando eles chegam aqui no bospital, eles chegam uma queixa assim [...] geral. Os sintomas que eles apresentam, as queixas que eles apresentam é a mesma que a maioria das pessoas tem. Então, assim, eu não faço distinção nenbuma. Não tem nenbum tratamento específico, nenbum encaminbamento específico. Pra mim, é igual o tratamento. O atendimento é igual pra todos, independentemente da classe. (Enfermeiro 1)

Albuquerque et al.$^{8}$ apontam para a fragilidade da relação profissional/usuário no que tange à comunicação, já que o fornecimento de algumas informações importantes muitas vezes não ocorre por conta da sexualidade e do estigma que a cerca, o que acarreta na perda de oportunidades para a promoção da saúde.

A narrativa - de todos os entrevistados - de que nunca receberam em seus plantões usuárias trans com queixas relacionadas ao processo de mudança corpórea, faz surgir um questionamento para o pesquisador: se já é constatado que esse processo ocorre com sujeitos dessa realidade e que, inclusive, é causa de sofrimento, por que essas usuárias não chegam ao serviço? E, se chegam, por que não são percebidos?

Eles vêm por queixas várias, não é nada assim que acometa só a eles não, mas atendemos muitos deles aqui. As queixas são normais (questiona-se sobre a utilização de bormônios). Até boje, não atendi ninguém por causa disso, é mais por acidente ou então por uma gripe ou alguma dor, algo assim. (Enfermeiro 2)

Apesar do receio de se comprometer ao longo da entrevista, e de negar a existência de preconceito na instituição, em dado momento, quando questionado de outra forma sobre preconceito, um dos enfermeiros descreve:

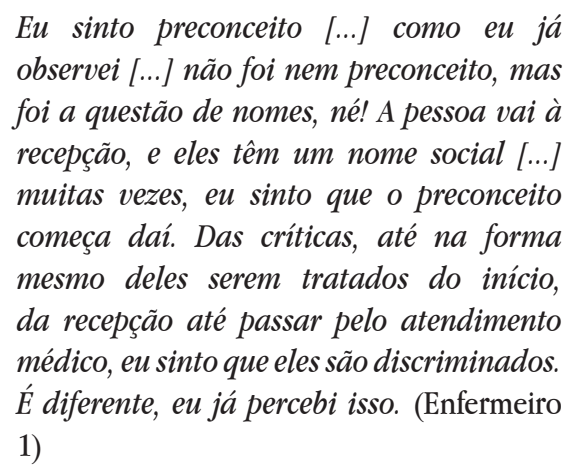

Outra usuária entrevistada descreve o preconceito associado às infecções sexualmente transmissíveis:

"[...] eles (profissionais) não têm a mente muito aberta, eu acho que eles não tão preparados pra trabalbar com o público em geral, porque, tipo, a maioria chega lá, eles tratam com descaso, olham torto pras 'trava', acham que a 'trava' tá indo lá porque a 'trava' tá doente, tá com alguma coisa que vai pegar tendo muito contato, eu acho que seja isso, eles não tão preparados pra atender." (Usuária 2)

Um dos trabalhadores corrobora o relato anterior da usuária, ao reconhecer o posicionamento de alguns colegas:

[...] eu vejo dessa forma, não é que eles (população LGBT) são [...] não é invisibilidade; é mais é preconceito mesmo! Preconceito de acreditar que são eles que podem transmitir doenças mais que os outros, que são eles que podem receber doenças mais que os outros [...] eu vejo mais como preconceito. (Enfermeiro 1)

Os profissionais relatam ainda ter pouco tempo para conhecer as políticas existentes e para produzir 
novos modos de cuidado. Percebe-se que a rotina e os plantões cansativos engessam esses trabalhadores e que o processo de formação na saúde deixa a desejar quando não se preocupa em promover sensibilidade e senso de corresponsabilização ao longo da graduação.

Abrahão e Merhy ${ }^{9}$ reconhecem que, quando a formação em saúde centra-se exclusivamente no saber científico, todo o universo que o usuário traz consigo é desconsiderado, reduzindo-o apenas à doença. Os autores destacam como consequência dessa aprendizagem, dentre outros, justamente o que é percebido também neste estudo: nos serviços, existência de barreiras ao acesso e distanciamento entre profissionais e usuárias. Dessa forma, a PNSILGBT não existe e não é efetiva na realidade pesquisada, refletindo negativamente na qualidade da assistência destinada a esse público, distanciando-o dos serviços de saúde.

\section{DISCUSSÃO}

Em virtude da ciência de que o acesso integral à saúde ainda não faz parte da realidade do Sistema Único de Saúde brasileiro e da vida da população LGBT, são mobilizados estudos e pesquisas para que se compreendam os entraves responsáveis por isso. Teixeira, Morais e Teixeira ${ }^{10}$ enumeram algumas das principais demandas trazidas por essas usuárias aos dispositivos de saúde, dentre elas, queixas com relação a conflitos familiares, rejeição, dificuldade na garantia do trabalho e no acesso aos medicamentos necessários, falta de espaço de inserção escolar, restrita rede de apoio, estigmas e preconceito social, que envolvem questões $-a$ priori - básicas hoje em dia com relação ao nome social e ao nome de registro.

Especificamente entre o público de transexuais e travestis, os riscos são mais evidentes, visto que o processo de mudança corpóreo se não recorrente, é desejado. Com o propósito de obter o corpo tão aspirado, nem sempre esses sujeitos valem-se dos métodos seguros e indicados. Apesar de almejado pela maioria, vale ressaltar que o processo transexualizador não é determinante para identificar a transexualidade, podendo um sujeito reconhecer-se trans sem que tenha se submetido a qualquer procedimento de modificação corporal.
Nogueira $^{11}$ considera o corpo como uma linguagem, sendo a representação de identidades e grupos. Nesse sentido, a remodelagem do corpo é tomada como produção e produto de significados, além da constituição e reconhecimento de si.

As situações mais recorrentes resultantes do processo transexualizador clandestino que chegam aos dispositivos vão desde o uso indiscriminado e sem orientação de hormônios e do silicone industrial, abuso de drogas, violência, até as queixas também derivadas de ordem social e psicológica. Logo, o acesso universal e a disponibilidade de serviços ofertados têm se mostrado imprescindíveis, aliados ao preconizado pelo SUS: prevenção, promoção e recuperação da saúde.

Para Carvalho ${ }^{12}$, o conceito de saúde se mostra como resultado de uma complexa produção social e está imbricado nas decisões políticas incidentes sobre os seus determinantes sociais. Louro ${ }^{13}$ destaca que a atual e progressiva aceitação dessa pluralidade por parte da sociedade não pode deixar de esquecer os embates já sofridose ainda recorrentes. Alguns segmentos tradicionais desejam retomar valores convencionais da família, excluindo esses modos de vida destoantes, utilizandose desde campanhas até manifestações de agressão, discursos de ódio e violência física. Albuquerque et al. ${ }^{8}$ sustentam que, mesmo que venham surgindo no Brasil buscas e conquistas no que tange ao direito de cidadania para a população homossexual, ainda há escassez de conhecimento quanto às suas necessidades em saúde. Logo, o conhecimento dessas necessidades é primordial para fomentar o desenvolvimento das políticas de saúde direcionadas à categoria. Tais políticas se mostram necessárias para o enfrentamento do preconceito cuja existência já fora reconhecida no âmbito da saúde.

Facchini ${ }^{14}$ presume que a resistência relacionada à procura dos serviços de saúde apresentada pela referida população evidencia a discriminação que ocorre por conta do contexto heterossexual dominante, da falta de qualificação e do preconceito dos trabalhadores da saúde diante dessas demandas. Desta forma, reconheceu-se que a violência e o estigma social sofrido pela orientação sexual e pela identidade de gênero afetam o processo de adoecimento e sofrimento, assim como dificultam o acesso à saúde, à educação, ao lazer, ao trabalho, dentre outros. 
Diante do exposto, emerge uma questão importante com relação à conduta dos profissionais da saúde diante das diferenças, dentre as quais se atenta aqui para a diversidade sexual. Para Abrahão e Merhy ${ }^{9}$, a formação dos trabalhadores da saúde deve ser um trabalho vivo, capaz de estar constantemente convocando novos métodos e técnicas de cuidado, que acompanhem e reconheçam as mudanças decorrentes da contemporaneidade.

A existência da Política Nacional de Saúde Integral LGBT vai muito além do que se propõe. Nesse sentido, Santos et al. 15:405 afirmam que "sua consequência mais significativa está na transformação do imaginário social, na superação dos preconceitos que permeiam a vida e as relações sociais e que se abatem marcadamente sobre esse público". Assim, o trabalhador da saúde é um sujeito detentor de uma história, pertencente a determinado contexto e cultura, e não está alheio ao imaginário social que o constitui e o cerca. Sendo resultado dessa construção social, ele age de acordo com ela onde quer que esteja, inclusive no âmbito de trabalho.

Consequentemente, o exercício das profissões está imbricado nos valores morais dos indivíduos, sendo que as atitudes e posturas tomadas variam de acordo com os valores que possuem. Entretanto, observa-se que tais valores interferem na qualidade da relação profissional/ usuário (vínculo), relação que se mostra de fundamental importância para a produção de saúde. Ademais, percebe-se que tais juízos de valor prejudicam ou até mesmo provocam distanciamento, chegando a impedir que o acolhimento e o processo de cuidado do usuário ocorram. Ainda em consonância com Santos et al. .5:405 $^{\text {a }}$ "qualquer forma de discriminação é fator limitante da saúde e promotor do adoecimento, inclusive a própria homofobia".

Assim, o atendimento à comunidade LGBTT nos serviços de saúde está permeado pelos dilemas socioculturais, visto que a relação entre profissional e usuário representa o encontro de mundos distintos - fato que seria amenizado por uma atuação profissional fundamentada nos princípios éticos ${ }^{15: 406}$.

Parker $^{16}$ afirma que o conceito de estigma deve ser pensado como um processo social ligado às relações de poder, dominação e controle. Logo, identificou-se que a reprodução do estigma reflete na valorização de determinados grupos sobre outros, esses últimos, na maioria das vezes, são marginalizados. O Ministério da Saúde, através da Secretaria de Gestão Estratégica e Participativa ${ }^{17}$, reforça que, para enfrentar tais estigmas, é necessário se atentar para o estabelecimento da democracia social e, com isso, buscar uma consciência sanitária implicada com a defesa do direito à saúde e dos direitos sexuais.

Os princípios da Lei Orgânica da Saúde ${ }^{18}$ prezam pela igualdade em todos os locais e níveis de assistência. No entanto, esta pesquisa apontou que existe uma ligação entre estigma e desigualdade social na realidade de travestis e transexuais. Em seu artigo $7^{\circ}$, essa lei garante, dentre outros: "I - universalidade de acesso aos serviços de saúde em todos os níveis de assistência; [...] III - preservação da autonomia das pessoas na defesa de sua integridade física e moral; IV - igualdade da assistência à saúde, sem preconceitos ou privilégios de qualquer espécie”. Para Ferreira, Pedrosa e Nascimento ${ }^{19}$, é imprescindível que o SUS crie estratégias para ofertar e acolher esse público, pois a maior dificuldade no acesso aos serviços se dá pelo fato de que esses sujeitos não são reconhecidos enquanto detentores de direitos, desejos, aspirações e contingências que lhes são próprios.

\section{CONCLUSÃO}

Tendo em vista todo o processo do presente estudo, a priori, fazem-se necessários o preparo e o conhecimento da Política Nacional de Saúde LGBT por parte não só das usuárias e dos profissionais da saúde, mas de toda a equipe que trabalha nos dispositivos. Além disso, é preciso refletir a respeito da atual conjuntura em que se encontra a saúde desse grupo, a fim de que se identifique as dificuldades de implantação das políticas que atendam efetivamente às suas demandas.

A compreensão de que existem determinantes sociais e demandas específicas - a depender do usuário - tornariam os trabalhadores da saúde mais sensíveis para perceber tais especificidades. Nesse sentido, pequenas atitudes como a preocupação com a utilização 
do nome social nos espaços se mostram eficazes no fazer e produzir saúde e no estabelecimento do vínculo profissional/usuário. É necessário um olhar diferenciado para o processo de formação dos profissionais de saúde. A consciência desde a graduação de que humanização e acolhimento devem ser encarados como uma postura de todos os profissionais dessa área.

Tal quadro demonstra a necessidade de um trabalho ético-estético na saúde, apartado de juízos de valor, comprometido com a supressão do preconceito, discriminação e violência (inclusive institucional), bem como de um posicionamento contrário à violação dos direitos humanos. É indispensável o investimento no preparo de profissionais da área para que estejam sensíveis e humanizados no atendimento dessas e de outras populações vulneráveis. Sensibilidade e empatia colaboram no estabelecimento do vínculo, contribuindo para a garantia e reconhecimento dos direitos, para promoção da cidadania, exercendo a produção de saúde e ampliando o acesso aos dispositivos disponíveis não só para esses, mas para todos os sujeitos.

Dessa forma, sugere-se que sejam realizadas outras investigações com esta temática em outros contextos, visto que o princípio da universalidade de acesso do SUS ainda não foi alcançado, na tentativa de identificar potenciais e dificuldades que possam contribuir no cuidado em saúde.

\section{REFERÊNCIAS}

1. Carrara S. Discriminação, políticas e direitos sexuais no Brasil. In: Monteiro S, Villela W, organizadores. Estigma e saúde. Rio de Janeiro: Fiocruz; 2013. p. 143-60.

2. Brasil. Ministério da Saúde. Política Nacional de Saúde Integral de Lésbicas, Gays, Bissexuais, Travestis e Transexuais - LGBT. Brasília; 2011.

3. Minayo MCS. Amostragem e saturação em pesquisa qualitativa: consensos e controvérsias. Rev Pesq Qualit [internet]. 2017 [acesso em 2018 Mar 22];5(7):1-12. Disponível em: https://editora.sepq.org.br/index.php/rpq/ article/view/82/59

4. Caregnato RCA, Mutti R. Pesquisa qualitativa: análise de discurso versus análise de conteúdo.
Texto \& Contexto Enferm [Internet]. 2006 [acesso em 2018 Mar 22];15(4):679-84. Disponível em: http://www.scielo.br/pdf/tce/v15n4/v15n4a17.pdf

5. Gill R. Análise de discurso. In: Bauer MW, Gaskell $\mathrm{G}$, organizadores. Pesquisa qualitativa com texto, imagem e som: um manual prático. 13. ed. Petropólis (RJ): Vozes; 2015. p. 244-70.

6. Ferreira MCL. Análise do Discurso e suas interfaces: o lugar do sujeito na trama do discurso. Organon [Internet]. 2010 [acesso em 2018 Mar 22];24(48). Disponível em: https://seer.ufrgs.br/organon/article/ view/28636/17316

7. Ganaza KLT, Romão PASS, Domingues RM, Teixeira JJV, Demarchi IG. Percepção e conscientização de universitários sobre o sistema único de saúde. Rev Saúde Pesq [Internet]. 2017 [acesso em 2018 Mar 22];10(3):519-30. Disponível em: http://periodicos. unicesumar.edu.br/index.php/saudpesq/article/ view/6227/3135

8. Albuquerque GA, Garcia CL, Alves MJH, Queiroz CMHT, Adami F. Homossexualidade e o direito à saúde: um desafio para as políticas públicas de saúde no Brasil. Saúde Debate [Internet]. 2013 [acesso em 2018 Mar 22];37(98):516-24. Disponível em: http://www.scielo.br/pdf/sdeb/v37n98/ a15v37n98.pdf

9. Abrahão AL, Merhy EE. Formação em saúde e micropolítica: sobre conceitos-ferramentas na prática de ensinar. Interface. Botucatu [Internet]. 2014 [acesso em 2018 Mar 22];18(49):313-24. Disponível em: http://www.scielo.br/pdf/icse/ v18n49/1807-5762-icse-18-49-0313.pdf

10. Teixeira AM, Morais JSN, Teixeira MPM. Transexualidade e travestilidade na saúde. In: Ministério da Saúde (BR). Secretaria de Gestão Estratégica e Participativa. Departamento de Apoio à Gestão Participativa. Transexualidade e travestilidade na saúde. Brasília: Ministério da Saúde; 2015. p. 83-98.

11. Nogueira FJS. A saga da beleza: um estudo das transformações corporais na 'experiência travesti' [dissertação]. João Pessoa: Universidade Federal da Paraíba; 2009. 135 p.

12. Carvalho AI. Determinantes sociais, econômicos e 
ambientais da saúde. In: Fundação Oswaldo Cruz. A saúde no Brasil em 2030: prospecção estratégica do sistema de saúde brasileiro: população e perfil sanitário [Internet]]. Rio de Janeiro: Fiocruz/ Ipea/Ministério da Saúde/Secretaria de Assuntos Estratégicos da Presidência da República, 2013 [acesso em 2018 Mar 22]. p. 19-38. Disponível em: http://books.scielo.org/id/8pmmy/pdf/ noronha-9788581100166-03.pdf

13. Louro GL. Destemidos, bravos e solitários: a masculinidade na versão western. Bagoas [internet]. 2013 [acesso em 2018 Mar 22];(10):17182. Disponível em: https://periodicos.ufrn.br/ bagoas/article/view/5382/4397

14. Facchini R. Prazer e perigo: situando debates e articulações entre gênero e sexualidade. Cad Pagu [Internet]. 2016 [acesso em 2018 Mar 22];(47): e164714. Disponível em: http://www.scielo.br/pdf/ cpa/n47/1809-4449-cpa-18094449201600470014. pdf

15. Santos AR, Santos RMM, Souza ML, Boery RNSO, Sena ELS, Yarid SD. Implicações bioéticas no atendimento de saúde ao público LGBTT. Rev Bioét [Internet]. 2015 [acesso em 2018 Mar 22];23(2):400-8. Disponível em: http://www.scielo. br/pdf/bioet/v23n2/1983-8034-bioet-23-2-0400.pdf

16. Parker R. Interseções entre estigma, preconceito e discriminação na saúde pública mundial. In: Monteiro S, Villela W, organizadores. Estigma e saúde. Rio de Janeiro: Fiocruz, 2013. p. 25-46.

17. Ministério da Saúde (BR). Secretaria de Gestão Estratégica e Participativa. Departamento de Apoio à Gestão Participativa. Política Nacional de Saúde Integral de Lésbicas, Gays, Bissexuais, Travestis e Transexuais. Brasília: ministério da Saúde; 2013.

18. Brasil. Ministério da Saúde. Lei no 8080, de 19 de setembro de 1990. Dispõe sobre as condições para promoção, proteção e recuperação da saúde, a organização e o financiamento dos serviços correspondentes e dá outras providências. Diário Oficial da União, Brasília, 20 set. 1990. Seção 1, p. 18055.

19. Ferreira BO, Pedrosa JIS, Nascimento EF. Diversidade de gênero e acesso ao SUS. Rev
Bras Promoç Saúde [Internet]. 2018 [acesso em 2018 Mar 30];31(1):1-10. Disponível em: http:// periodicos.unifor.br/RBPS/article/view/6726/pdf

Recebido em: 13/01/2019

Aceito em: 20/08/2019 